\title{
Incomplete Contracts and Firm Boundaries: New Directions
}

\author{
Wouter Dessein* \\ Columbia University, Graduate School of Business
}

\begin{abstract}
The seminal work by Grossman and Hart (1986 "The Costs and Benefits of Ownership: A Theory of Vertical and Lateral Integration", 94 Journal of Political Economy 691-19.) made the study of firm boundaries susceptible to formal economic analysis, and illuminated an important role for markets in providing incentives. In this essay, I discuss some new directions that the literature has taken since. As a central challenge, I identify the need to provide a formal theory of the firm in which managerial direction and bureaucratic decision-making play a key role. Merging a number of existing incomplete contracting models, I propose two approaches with very different contracting assumptions. As in transaction cost economics, a central element in those theories is the presence of a central office that directs and coordinates the actions of subordinates. More novel, I highlight the superior ability of nonintegrated firms to adapt to a changing environment. JEL: D23, D83, D86, L22, L23.
\end{abstract}

\section{Introduction}

In the last 25 years, a formal literature has developed, which analyzes firm boundaries and institutional choice, building on the incomplete contracting framework proposed by Grossman and Hart (1986) (GH hereafter). In this article, I discuss some new directions that the literature has taken since. As a central challenge for the literature, I identify the need to provide a theory of the firm in which management and bureaucratic decision-making play an important role in coordinating economic activity. Merging a number of existing incomplete contracting models, I propose two ways to integrate managerial direction in a theory of the firm.

A major contribution of $\mathrm{GH}$ has been to provide scholars with the tools necessary to study the boundaries of the firm in a clear and consistent way. GH provide a parsimonious and formally tractable definition of what constitutes a firm and how it differs from the market

\footnotetext{
*Wouter Dessein, Columbia University, Graduate School of Business, New York, NY. Email: wd2179@columbia.edu. I would like to thank Patrick Bolton, Bengt Holmstrom, Navin Kartik, Tano Santos, and Steve Tadelis for very useful discussions on this topic and Rob Gertner, Bob Gibbons, and Niko Matouschek for the comments on a earlier draft. This article grew out of a presentation prepared for the "Grossman and Hart at 25" conference held in Brussels on June 24-26, 2011.
}

The Journal of Law, Economics, and Organization, Vol. 0, No. 0 doi:10.1093/jleo/ews044 
or "non-integration". ${ }^{1}$ Firms are identified with asset ownership and residual control rights, and integration with joint ownership. Firm Boundaries matter because contracts are incomplete, and ownership provides residual decision rights over the use of the firm's nonhuman assets, that is the rights to use assets in whatever way the owner likes unless otherwise prohibited in a contract.

Unlike the preceding informal theories (Coase 1937; Williamson 1971), $\mathrm{GH}$ and the property rights theory (PRT) of the firm (see also Hart and Moore 1990; Hart 1995) provide a clear identification of the benefits of nonintegration. ${ }^{2}$ In the theory, ownership of an asset increases the bargaining power of a player. In most versions of $\mathrm{GH}$, an independent supplier is therefore more motivated - has higher powered incentives to make noncontractible relation-specific investments - than an integrated supplier. ${ }^{3}$ As noted by Holmstrom and Roberts (1998), however, firms are rather poorly defined in the property rights model. There is no management or headquarters in the theory, just a buyer and a seller who trade in a decentralized way. It is further not clear how one can scale up the model to make it relevant to large organizations where residual control over all assets involved in production are exercised by a central office on behalf of the firm, and employees simply contribute human capital (Holmstrom 1999; Williamson 2002).

In this article, I discuss two modeling approaches that introduce managerial direction and authoritative decision-making in a formal theory of the firm. In the proposed models, managers are different from production workers in that they are not strictly needed for production. Rather their role is to coordinate and direct production by other agents. ${ }^{4}$ Importantly, this ability of the managers to coordinate is compromised under nonintegration. In particular, in the proposed models, asset ownership allows owners or their designated managers to direct the actions or decisions of

1. See Aghion and Holden (2011) for an excellent nontechnical exposition of the Grossman and Hart model, and Holmstrom (1999) for a more detailed critical assessment.

2. More recent contributions to the PRT have broadened the concept of ownership to that of access (Rajan and Zingales 1998) and extended the theory to incorporate dynamic considerations and relational contracting (Baker et al. 2002). Whinston and Segal (2010) provide a comprehensive overview and analysis of property rights models.

3. Empirical support for this can be found in Woodruff (2002), Baker and Hubbard (2003), Acemoglu et al. (2010), as well as in the literature on franchising and manufacturer-retailer relationships, as surveyed by Lafontaine and Slade (2007). More generally, it is optimal to assign asset ownership to the party who must make the most important noncontractible relationship-specific investments. As has been noted by other authors, however, the latter prediction may depend on often subtle details of the model (see, e.g., Holmstrom and Roberts 1998; Whinston 2003). The only general insight is that asset ownership affects investments.

4. I do not emphasize the difference between management and the owners of the firm. Managers could be the owners of the firm, or temporarily delegated (loaned) the residual control rights over the assets of the firm. As such, I also ignore any of the incentive problems between the owners and the managers that have been the subject of much research in corporate finance. 
employees in a way they would be unable to do, say, with an independent supplier.

Both modeling approaches draw largely on existing incomplete contracting models, but differ substantially in their contractual assumptions. The common feature is that both assume that actions are ex post noncontractible and, hence, the ability to direct and control behavior of agents is fundamentally different under integration and nonintegration. In contrast, in traditional property rights models, residual control rights do not affect ex post decision-making as they simply affect threat points under friction-less coasian bargaining. ${ }^{5}$ Conceptually, the proposed models are therefore closer to the informal theories proposed by Coase (1937) and Williamson (1971, 1975, 1985), who identified firms with decision-making by command. Both approaches, however, follow GH in proposing theories that provide a unified account of both the cost and the benefits of integration. Moreover, as in $\mathrm{GH}$, firms remain defined in terms of residual control rights over nonhuman assets.

The remainder of the article goes as follows. In Section 2, I discuss what I refer to as "moral hazard theories" of the firm. In those theories, the relevant actions are controlled by the agents or "implementers" of the firm (as opposed to the owners of the firm or their designated managers). Since actions are noncontractible, they are formally equivalent to "effort" in standard moral hazard models. Owners or management of the firm can influence those actions only indirectly by giving directions which agents (or suppliers) must be willing to follow. In contrast, in Section 3, I discuss "control theories" of the firm, where asset ownership is assumed to provide direct control over the relevant actions. Since those actions are again noncontractible, residual control rights do not serve as a bargaining tool as in $\mathrm{GH}$, but they are exercised in equilibrium. Section 4 summarizes and concludes.

\section{Moral Hazard Theories of the Firm}

A direct implication of contractual incompleteness is that contracting on cost and revenue streams is likely to be imperfect. As Holmstrom and Tirole (1989) argue

Ownership provides residual rights to all kind of assets, physical as well as financial. The right of a residual return stream is after all nothing more than a right to decide how to spend the firm's money, which has not been explicitly contracted for.

5. The property rights literature, instead, focuses on the impact of asset ownership on ex ante noncontractible investments, for example, in relation-specific human capital. 
Moral hazard theories of the firm focus on this aspect of incomplete contracts. ${ }^{6}$ Other ways in which residual control rights might matter, such as direct control over actions, are minimized by assuming that all actions are both inalienable and noncontractible. That is, actions are like effort in standard moral hazard models. Asset ownership then matters only to the extent it provides parties with income streams - or makes them responsible for financial outlays - that otherwise cannot be contractually assigned. Residual control right, for example, may allow owners to appropriate part of the returns of the assets under their control, as in Hart (1988), Stein (1997), or Hart and Holmstrom (2010). Noncontractible effort may further affect the future profitability or resale value of the assets, as in Holmstrom and Milgrom (1991, 1994) and Baker and Hubbard (2003, 2004), and it may be difficult to contract on this resale value.

In its simplest incarnation, where actions are modeled as one-dimensional effort, this approach transforms the asset ownership problem into a moral hazard in teams problem with budget balance. Just as there are only so much bargaining chips to go around in the standard property rights model, there are now only so many residual income rights to be allocated. Allocating more assets to one party increases the latter's incentives, but unavoidably reduces the incentives of another party. As in the traditional PRT models, assets should then be allocated to the party whose effort is most important. ${ }^{7}$ This simple model, therefore, does not break much new ground relative to PRT. ${ }^{8}$ In order to develop a theory of the firm in which managerial direction plays a meaningful role, the remainder of this section considers a model in which actions or effort are multidimensional, as in Holmstrom and Milgrom (1991, 1994). I first provide an informal discussion of the model and the related literature with the formal model being presented in Section 2.2.

\footnotetext{
6. In their book on the "Economics of Property Rights," Furubotn and Pejovich (1974: 4) argue that the rights of ownership of an asset include (a) the right to use the asset, (b) the right to appropriate returns from the assets, and (c) the right to change the form and/or substance of an asset.

7. While theoretically less interesting, this model is more tractable than the classic PRT model and its implications are less susceptible to particular assumptions about bargaining protocols or outside options (De Meza and Lockwood 1998). Moreover, the interpretation of noncontractible relationship-specific investments can be broadened to include effort more broadly. This increases the applicability of the model, and makes it more applicable to, say, franchising contracts (Bhattacharyya and Lafontaine 1995; Lafontaine and Slade 2007).

8. An important exception is the famous paper by Alchian and Demsetz (1972) who proposed the concentration of profits shares in the hands of a specialized monitor as a solution to the moral hazard in team's problem. As they argued, such a monitor could overcome the noncontractibility problem by effectively measuring inputs of individual workers and mete out the appropriate rewards. As the focus of this article is on formal theories, I refer to Holmstrom and Tirole (1989) for a discussion of Alchian and Demsetz and its shortcomings as a workable theory of the firm.
} 


\subsection{Managerial Direction in a Theory of the Firm}

Consider a firm that manufactures, markets, and sells a product and where production requires the firm to make a specialized input (integration) or buy it from an independent supplier (nonintegration). Producing this specialized input requires both human capital and the use of some dedicated assets. Under nonintegration, asset ownership by an independent supplier increases the latter's incentives for cost minimization - as the supplier must provide, maintain, and manage all the necessary assets for production (machines, materials, real estate, working capital) and incurs all the associated financial outlays. In contrast, under integration, the firm provides all the necessary assets and incurs the associated financial outlays. The supplier is then an employee who provides only human capital. While the firm and the supplier may contract on cost measures, those measures are very noisy. At the optimum, the wage paid to a supplier-employee, or the price paid for the input to an independent supplier, is therefore not very sensitive to the actual production costs of the input.

Drawing on Holmstrom and Milgrom (1991, 1994), a theory of the firm can then be obtained in which asset ownership by a firm increases the ability of the firm owners or their designated managers to steer, direct, and coordinate the efforts of an employee in a way they cannot steer the effort of an independent supplier. In particular, I assume the supplier can undertake actions that improve coordination and the compatibility of the input, but that also increase the cost of the input. ${ }^{9}$ The role of management is to identify which coordinating actions are worthwhile and direct the supplier to undertake those. Since actions are noncontractible, however, directions take the form of orders - modeled as cheap talk - which employees must be willing to follow. Nonintegration reduces the ability of management to direct the supplier who may balk when efficient, but cost-increasing actions are requested. Indeed, nonintegration results in high-powered incentives for cost reduction by an independently operated supplier. In contrast, under integration, the employee-operated supplier has a limited stake in cost reductions. While the employee-supplier is then less entrepreneurial, diligent, and motivated to reduce costs, management will find it much easier to direct and steer the actions of this employeesupplier toward coordination and compatibility.

The model, formally developed in Section 2.2, shows how incomplete contracting models can provide a foundation for the idea, central to transaction cost economics and Coase (1937), that firms distinguish themselves from markets by their ability to coordinate economic activity through bureaucratic decision-making. It further provides a number of testable predictions for integration decisions. First, the model delivers the insight, prominently featured in Roberts (2004), that the choice between firms and markets involves a tradeoff between motivation and coordination.

9. I follow the approach in Dessein et al. (2010) to model such coordinating actions. 
I show that integration is more likely to be optimal when coordination is more important or noncontractible effort is less important. Second, the model allows us to analyze how optimal integration decisions are affected by the contractibility of input measures, such as costs and output measures, such as gross profits or revenues. Perhaps counterintuitively, the impact of a better contractibility of input costs on firm boundaries is shown to be ambiguous. On the one hand, a better contractibility of costs allows for more efficient cost-plus contracting with an independent supplier. Such cost-plus contracting facilitates coordination with an independent supplier who is then more willing to follow orders. On the other hand, a better contractibility of costs also allows the firm to provide higher powered incentives for cost-reduction to an employee and, hence, duplicate the benefits from asset ownership within its boundaries. It follows that an improved contractibility of input costs mitigates agency problems both inside firms and between firms. Section 2.2 provides exact conditions for when it favors (non)integration. In contrast, I show that a better contractibility of gross profits/revenues tends to favor nonintegration as contracting on output measures only serves to improve coordination.

The above theory of the firm boundaries draws heavily upon on the insights and models by Holmstrom and Milgrom whose focus was on in-house versus independent sales agents. ${ }^{10}$ In addition, the tradeoff between coordination and motivation also plays a central role in the models by Athey and Roberts (2001), Dessein et al. (2010), and Friebel and Raith (2010). A similar tradeoff further arises in the choice between fixed price and cost-plus incentive contracting, as studied in Bajari and Tadelis (2001). The low-powered incentives associated with cost-plus incentive contracting allow for more flexible renegotiation when ex post adaptation is required, but it also creates limited incentives for cost reduction through privately costly effort. Put differently, a buyer has more control over a seller when the latter is motivated by a cost-plus contract than by a fixed price contract. Building on this article, Tadelis (2003) provides reducedform foundations for transaction cost economics. Finally, obedience or the willingness to follow orders has previously been studied by Van den Steen (2007, 2010) and Marino et al. (2010). Van den Steen (2010) follows $\mathrm{GH}$ in that asset ownership affects the outside options of the players. Moving asset ownership from the agent to the principal then lowers the outside option of the agent and raises that of the principal. It therefore makes it more costly for the agent to get fired and easier for the principal to commit to firing a disobeying agent. Van den Steen (2007) does not

10. Baker et al. (2002) provide a dynamic version of Holmstrom and Milgrom, where the principal offers a relational rather than a formal contract to the supplier. As in Holmstrom and Milgrom, integration results in lower powered but more balanced incentives than nonintegration. Their model, however, is much closer to the original PRT model in that they explicit model trading decisions, bargaining, and hold-up. 
study firm boundaries, but emphasizes that high-powered incentives come at the expense of more disobedience.

\subsection{A Model of Managerial Direction}

I now formally develop a simple moral hazard theory of the firm, based on Holmstrom and Milgrom (1991, 1994) and Dessein et al. (2010). A firm manufactures, markets, and sells a product. I take it as given that the firm owns all the assets necessary for manufacturing, marketing, and selling the product. Production, however, also requires that the firm makes or buys a specialized input. ${ }^{11}$ Making this specialized input requires both human capital and the use of some dedicated assets. Under integration, the firm provides and owns the dedicated assets, and an employee of the firm provides human capital. Under nonintegration, the provider of human capital also provides and owns the dedicated assets. I will refer to both the employee (under integration) and the owner-operator (under nonintegration) as the agent, unless it is necessary to distinguish the two.

2.2.1 Input Cost. The cost of the input depends on some effort $e$ provided by the Agent at a private cost $e^{2} / 2$. In addition, the Agent takes a continuum of noncontractible actions $i \in[0,1]$, each of which may increase the gross profits of the firm. For example, such actions may improve the coordination with other business units or make the input more compatible. Each of these actions, however, also increases the cost of the input. Formally, the production cost of the input, gross of any effort costs, equals

$C=\mathbb{C}-v e+\int_{0}^{1} I_{i} k_{i} d i$,

where $v$ is the marginal value of effort,

$I_{i}= \begin{cases}1 & \text { if the coordinating action } i \text { is undertaken } \\ 0 & \text { if the coordinating action } i \text { is not undertaken. }\end{cases}$

and $k_{i}$ is an i.i.d random variable, uniformly distributed on $[0,1]$.

2.2.2 Gross Profits. Profits of the firm, gross of the cost of the input, and any transfer to the agent equal

$R=\Psi+\int_{0}^{1} I_{i} \Delta_{i} d i$

where $\Delta_{i} \in\{0,1\}$ is an i.i.d random variable with $E\left(\Delta_{i}\right)=p$. The parameter $p$ can be interpreted as the value or importance of coordination.

11. The only role that asset specificity plays in the model is conceptual: there is no competitive input market from which the firm can buy this input, or to whom the supplier can sell his input. 
2.2.3 Firm Boundaries. Under nonintegration, the owner-operator provides all the machines, real estate, materials, and working capital necessary for production of the input. As a result, the owner-operator incurs the cost $C$ in addition to his private effort cost $e^{2} / 2$. Under integration, this cost $C$ is incurred by the firm, who then provides and controls all assets necessary for production. Similarly, since the firm controls all the other production activities (manufacturing, marketing, and selling) and provides the necessary assets, the firm is always residual claimant of the gross profit stream $R$. The model envisions a setting in which the firm is much larger than the supplier, and where the firm's owners are necessarily passive investors. Hence, unlike in $\mathrm{GH}$, there is no difference between forward and backward integration. ${ }^{12}$

2.2.4 Management and Managerial Direction. The residual control rights over the assets of the firm are delegated to a manager (or central office) who is not engaged in production but maximizes expected firm profits, for example, because she can divert part of the profits of the firm (Hart 1988; Stein 1997; Hart and Holmstrom 2010). ${ }^{13}$ While not essential for the results, I assume that only management of the firm observes $\Delta_{i} \in\{0,1\}$, but she can make a cheap talk statement regarding $\Delta_{i}$ to the Agent. Without loss of generality, I restrict cheap talk to a continuum of messages $m_{i} \in\{0,1\}$, for $i \in[0,1]$, where $m_{i}$ can be interpreted as an order or request by management of the firm to the Agent to choose $I_{i}=m_{i}$. One role for management is thus to coordinate and direct the activities of the Agent so that externalities with other activities of the firm are taken into account. In particular, since $k_{i}$ is uniformly distributed on $[0,1]$, the Agent should take the coordinating action $i$ whenever $\Delta_{i}=1$.

2.2.5 Contracting. While $R$ and $C$ are not contractible, there exists a correlated cost stream $P_{c}=C+c+\varepsilon_{c}$ and a correlated gross profit stream $P_{r}=R+r+\varepsilon_{r}$, where $\varepsilon_{c}$ and $\varepsilon_{r}$ are random variables with $\varepsilon_{c} \sim N\left(0, \sigma_{c}^{2}\right)$ and $\varepsilon_{r} \sim N\left(0, \sigma_{r}^{2}\right)$. The constants $c$ and $r$ reflect predictable differences between real and measurable cost and revenues. ${ }^{14}$ Without loss of generality, I set $r=c=0$. At the optimum, any transfer $t$ from the firm to the agent will be contingent on the realization of $P_{c}$ and $P_{r}$. I follow Holmstrom and

12. See also note13.

13. In particular, managing the firm is not compatible with providing the human capital and effort $e$ required for the specialized input.

14. Hence, $r<0$ represents a case where contractible gross profits substantially understate the true profitability of a product, for example, because management can manipulate accounting processes to divert revenues to other products and allocate costs from other business units to this product. 
Milgrom by considering only transfers that are a linear function of $P_{c}$ and $P_{r}$, that is: ${ }^{15}$

$t^{g}=b_{0}^{g}+b_{r}^{g} P_{r}-b_{c}^{g} P_{c}, \quad g=I, \mathrm{NI}$.

From equations (1) and (2), for a given equilibrium in pure strategies, the revenue and cost streams $R$ and $C$ are predictable ex ante. ${ }^{16}$ Hence, $t^{I}$ and $t^{N I}$ are normally distributed with

$\operatorname{Var}\left(t^{g}\right)=\left(\sigma_{c} b_{c}^{g}\right)^{2}+\left(\sigma_{r} b_{r}^{g}\right)^{2}, \quad g=I, \mathrm{NI}$.

As in Holmstrom and Milgrom, the agent is assumed to be risk averse with CARA utility, so he maximizes

$U_{A}^{I}=E\left(t^{I}\right)-\operatorname{Var}\left(t^{I}\right)-e^{2} / 2$

under integration, and

$U_{A}^{\mathrm{NI}}=E\left(t^{\mathrm{NI}}-C\right)-\operatorname{Var}\left(t^{\mathrm{NI}}\right)-e^{2} / 2$

under nonintegration. Similarly, the manager of the firm maximizes

$U_{M}^{I}=R-E\left(t^{I}-C\right)$

under integration, and

$U_{M}^{\mathrm{NI}}=R-E\left(t^{\mathrm{NI}}\right)$

under nonintegration.

2.2.6 Expected Firm Profits. Figure 1 summarizes the timing of the model. I assume that there is a competitive market of suppliers and employees at the contracting stage. The firm therefore can make a take-it-or-leave-it offer to the agent, where I normalize the reservation utility of the agent to

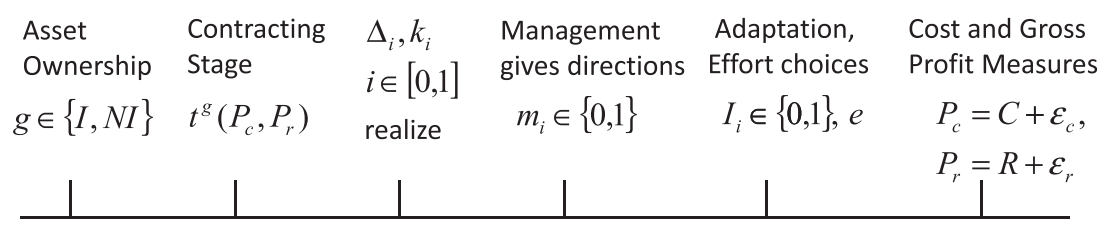

Figure 1. Time-line Moral Hazard Model.

15. See Holmstrom and Milgrom (1987) for a justification of the linearity assumption.

16. While a given coordination decision $I_{i}$ is not predictable ex ante, there is a continuum of coordinating decisions $I_{i}$. Moreover, for a given equilibrium in pure strategies, each of these decisions is a deterministic function of $k_{i}$ and $\Delta_{i}$, both i.i.d random variables. 
zero. Expected profits under integration and nonintegration can therefore be written as

$\pi^{g}=\Psi-\mathbb{C}+\int_{0}^{1} I_{i}\left(\Delta_{i}-k_{i}\right) d i+v e-e^{2} / 2-\left(\sigma_{c} b_{c}^{g}\right)^{2}-\left(\sigma_{r} b_{r}^{g}\right)^{2}, \quad g=I, \mathrm{NI}$

2.2.7 Managerial Direction. In the model, Management sends cheap talk messages $m_{i} \in\{0,1\}$, for $i \in[0,1]$. One can verify that there always exists an equilibrium of the communication subgame where management sends $m_{i}=1$, if and only if $\Delta_{i}=1$ and hence $I_{i}=1$ is the efficient action. ${ }^{17}$ I will focus on this truthful equilibrium. A cheap talk message of $m_{i}=1$ can then be interpreted as a request by management to take the coordinating action. Given truth-telling, a managerial direction to take a coordinating action will be followed by the agent if and only if

$k_{i} b_{c}^{I}<b_{r}^{I}$

under integration and

$k_{i}\left(1+b_{c}^{\mathrm{NI}}\right)<b_{r}^{\mathrm{NI}}$,

under nonintegration. ${ }^{18}$ Given the above incentive constraints, I define (the effectiveness of) managerial direction under integration and nonintegration by

$\alpha^{I} \equiv b_{r}^{I} / b_{c}^{I} \quad$ and $\quad \alpha^{\mathrm{NI}} \equiv b_{\mathrm{r}}^{\mathrm{NI}} /\left(1+b_{\mathrm{c}}^{\mathrm{NI}}\right)$

Indeed, given that $k$ is uniformly distributed on $[0,1], \alpha^{\mathrm{I}}$ and $\alpha^{\mathrm{NI}}$ are the probabilities that the agent follows the direction of management to take the coordinating action under integration and nonintegration, respectively. It follows that

$\int_{0}^{1} I_{i}\left(\Delta_{i}-k_{i}\right) d i=p \int_{0}^{\alpha^{g}}(1-k) d k=\frac{p}{2} \alpha^{g}\left(2-\alpha^{g}\right)$,

under both integration and nonintegration.

2.2.8 Effort Choices. From equation (3), effort under integration equals $e^{I}=v b_{c}^{I}$. From equation (4), effort under nonintegration equals $e^{\mathrm{NI}}=v\left(1+b_{c}^{\mathrm{NI}}\right)$. It will be useful to denote effort incentives under integration and nonintegration by

$\beta^{I} \equiv b_{c}^{I} \quad$ and $\quad \beta^{\mathrm{NI}} \equiv 1+b_{\mathrm{c}}^{\mathrm{NI}}$

17. The incentive constraint to reveal that $\Delta_{i}=0$ is that $\beta^{g}$, defined in equation (7), is smaller than 1 . This is always satisfied at the optimum. A sufficient condition to reveal that $\Delta_{i}=1$ is $1-\beta^{g} \leq 1-b_{r}^{g}$, which is also always satisfied at the optimum.

18. Given truth-telling, it will be easy to verify that the agent never has an incentive to take a coordinating action when $m_{i}=\Delta_{i}=0$. 
Under both structures, equilibrium effort is then given by

$e^{g}=v \beta^{g}, \quad g=I, N I$.

2.2.9 Tradeoff between Motivation and Coordination. In what follows, without loss of generality, I will optimize over $\beta^{g}$ and $\alpha^{g}$, that is "effort incentives" and "managerial direction," rather than the cost and revenue shares $b_{c}^{g}$ and $b_{r}^{g}$. Substituting equations (5-8), expected profits under integration can be rewritten as

$$
\begin{aligned}
\pi^{I}= & \Psi-\mathbb{C}+\frac{p}{2} \alpha^{I}\left(2-\alpha^{I}\right)+\frac{v^{2}}{2} \beta^{I}\left(2-\beta^{I}\right) \\
& -\sigma_{c}^{2}\left(\beta^{I}\right)^{2}-\sigma_{r}^{2}\left(\alpha^{I} \beta^{I}\right)^{2},
\end{aligned}
$$

whereas expected profits under nonintegration equal

$$
\begin{aligned}
\pi^{\mathrm{NI}}= & \Psi-\mathbb{C}+\frac{p}{2} \alpha^{\mathrm{NI}}\left(2-\alpha^{\mathrm{NI}}\right)+\frac{v^{2}}{2} \beta^{\mathrm{NI}}\left(2-\beta^{\mathrm{NI}}\right) \\
& -\sigma_{c}^{2}\left(\beta^{\mathrm{NI}}-1\right)^{2}-\sigma_{r}^{2}\left(\alpha^{\mathrm{NI}} \beta^{\mathrm{NI}}\right)^{2}
\end{aligned}
$$

First-order conditions with respect to effort incentives $\left(\beta^{g}\right)$ yield:

$b_{c}^{I} \equiv \beta^{I}=\frac{v^{2}}{v^{2}+2 \sigma_{c}^{2}+2 \sigma_{r}^{2}\left(\alpha^{I}\right)^{2}}$

and

$$
1+b_{c}^{\mathrm{NI}} \equiv \beta^{\mathrm{NI}}=\frac{v^{2}+2 \sigma_{c}^{2}}{v^{2}+2 \sigma_{c}^{2}+2 \sigma_{r}^{2}\left(\alpha^{\mathrm{NI}}\right)^{2}}
$$

First-order conditions with respect to managerial direction $\left(\alpha^{g}\right)$ yield $\alpha^{g}=\frac{p}{p+2 \sigma_{r}^{2}\left(\beta^{g}\right)^{2}} \quad g=I, \mathrm{NI}$

An inspection of the above equalities yields the following implications:

\section{Proposition 1.}

- $\beta^{\mathrm{NI}}>\beta^{I}$ and $\alpha^{I}>\alpha^{\mathrm{NI}}$ : Effort incentives are larger under nonintegration, but managerial direction is more effective under integration. Both are below first-best: $\beta^{g} \in(0,1)$ and $\alpha^{g} \in(0,1)$.

- Nonintegration features cost-plus contracting: the transfer to the supplier $t^{\mathrm{NI}}$ is increasing in the cost measure $\mathrm{P}_{\mathrm{c}}$. Integration features incentive contracting: the transfer to the employee $t^{I}$ is decreasing in the cost measure $P_{c}$.

It is further easy to verify that expected profits under integration, $\pi^{I}$, are supermodular in $\beta^{I},\left(-\alpha^{I}\right), v,(-p)$, and $\left(-\sigma_{c}^{2}\right)$. Similarly, expected profits 
under nonintegration are supermodular in $\beta^{\mathrm{NI}},\left(-\alpha^{\mathrm{NI}}\right), v,(-p)$, and $\sigma_{c}^{2}$ for $\beta^{\mathrm{NI}} \in[0,1]$. This yield the following comparative static results:

\section{Proposition 2.}

- An increase in the value of effort, $v$, increases effort incentives and decreases managerial direction. An increase in the importance of coordination, $p$, reduces effort incentives but increases managerial direction.

- Under nonintegration, an increase in the noisiness of cost measures, $\sigma_{c}^{2}$, increases effort incentives $\beta^{\mathrm{g}}$ and reduces managerial direction $\alpha^{\mathrm{g}}$. Under integration, opposite comparative statics hold.

This first set of results clearly shows a tradeoff between motivation (incentives) and coordination. First, this tradeoff is present for a given governance structure: more effort incentives come at the expense of less effective managerial direction, and both are at a second-best level at the optimum. In contracting with the agent (employee or supplier), management balances these two conflicting objectives. Interestingly, when contracting with a supplier, the cost measure is used to improve managerial direction, and transfers reward the supplier for having higher costs. This is akin to the cost-plus contracts studied in Bajari and Tadelis (2001). The aim of such "cost-plus" contracting is to improve the effectiveness of managerial direction. In contrast, when contracting in-house with an employee, the cost measure is used to increase motivation, and the employee is rewarded for reducing costs.

Second, this tradeoff is also present between governance structures: integration results in better coordination, but nonintegration results in better motivation. This suggests that as coordination becomes more important, integration will be preferred, whereas nonintegration will be preferred when motivation become more important. The following proposition states this result formally ${ }^{19}$ :

Proposition 3. An increase in the importance of cost-reducing effort, $v$, favors nonintegration. An increase in the importance of coordination, $p$, favors integration. For $v$ sufficiently small, integration is always optimal, whereas for $\mathrm{p}$ sufficiently small, nonintegration is preferred.

Finally, the model allows us to analyze how integration decisions respond to the contractibility of input costs and gross profits. Consider first the contractibility of input costs. Using the envelope theorem, it follows

19. The comparative static result can be obtained by taking the derivative of the profit functions (9) and (10) with respect to $v$ and $p$. Using the envelope theorem and the fact that $\beta^{\mathrm{NI}}\left(2-\beta^{\mathrm{NI}}\right)>\beta^{I}\left(2-\beta^{I}\right)$, but $\alpha^{\mathrm{NI}}\left(2-\alpha^{\mathrm{NI}}\right)<\alpha^{I}\left(2-\alpha^{I}\right)$, the result follows directly. It is further direct to show that integration (nonintegration) is optimal for $v=0(p=0)$. The last part of the proposition then holds by continuity. 
from profit functions (9) and (10), that a better contractibility of input costs (a decrease in $\sigma_{c}^{2}$ ) favors integration if and only if

$\beta^{I}>1-\beta^{\mathrm{NI}}$

We further have that both $\beta^{I}$ and $\beta^{\mathrm{NI}}$ are increasing in $v$ and decreasing in p. Moreover, $\beta^{I}=0<1-\beta^{\mathrm{NI}}$ for $v=0$, whereas $\beta^{I}>1-\beta^{\mathrm{NI}}=0$ for $p=0$. This yields the following result

Proposition 4. The impact of a better contractibility of input costs, as measured by $1 / \sigma_{c}^{2}$, depends on the value of effort $v$ and the importance of coordination $p$. Fix $\sigma_{r}^{2}$, then there exists a $\bar{v}\left(p, \sigma_{r}^{2}\right)>0$ and $\bar{p}\left(v, \sigma_{r}^{2}\right)>0$, such that a better contractibility of input costs favors integration if and only if $v>\bar{v}$ or $p<\bar{p}$.

Intuitively, a better contractibility of input costs has two opposite effects. On the one hand, it makes cost-plus contracting more efficient, and therefore allows for a better coordination under nonintegration. On the other hand, it allows for a more efficient provision of cost-cutting incentives to an employee, which favors integration. If the optimal level of effort incentives is relatively high (that is $v$ is large or $p$ is small), a better contractibility of input costs may then result in a shift from nonintegration to integration, but never the other way around. The opposite effect arises when optimal effort incentives are low.

Finally, consider the contractibility of gross profits, $1 / \sigma_{r}^{2}$, which can also be interpreted as the ability to contract on performance measures other than costs, such as quality, compatibility, cooperation, and so on, which are not rewarded by asset ownership. While no general results can be obtained, ${ }^{20}$ some insight can be provided by focusing on cases where such performance measures are either very precise ( $\sigma_{r}^{2}$ is small) or, instead, very noisy $\left(\sigma_{r}^{2}\right.$ large):

Proposition 5. Assume $p>v^{2}$, then there exists $r_{H}>r_{L}>0$, such that integration is preferred if performance measures on dimensions other than cost are very noisy, that is $\sigma_{r}^{2}>r_{H}$, whereas nonintegration is preferred if such performance measures are very precise, that is when $\sigma_{r}^{2}<r_{L}$.

Proof. Assume $1 / \sigma_{r}^{2}=0$. Under nonintegration, then $\beta^{\mathrm{NI}}=1$ and $\alpha^{\mathrm{NI}}=0$. Under Integration, we either have $\beta^{I}=0$ and $\alpha^{I}=0$, or $\beta^{I} \in(0,1)$ and $\alpha^{I}=0$. The latter case, however, is always dominated by nonintegration. From equations (9) and (10), one can then verify that integration will be preferred over nonintegration if and only if $p>v^{2}$. Continuity of profits in $\sigma_{r}^{2}$ implies that integration will be preferred for $p>v^{2}$ as long as $\sigma_{r}^{2}$ is large enough. Consider next $\sigma_{r}^{2}=0$. Nonintegration then achieves first-best, as $\beta^{\mathrm{NI}}=\alpha^{\mathrm{NI}}=1$, whereas effort is still second-best under nonintegration. Continuity of profits in $\sigma_{r}^{2}$ again

20. Indeed, profits are not supermodular in $1 / \sigma_{r}^{2}$. 
implies that nonintegration will be preferred as long as $\sigma_{r}^{2}$ is sufficiently small.

Proposition 5 is strongly suggestive that a better contractibility of other dimensions than input costs favors using nonintegration, as this allows to exploit the strong cost incentives provided by asset ownership. In contrast, if those other dimensions are hard to measure, there is a tradeoff between effort incentives and managerial direction.

In conclusion, the simple multitasking model above shows how, in a relative parsimonious way, moral hazard models can give content to a theory of managerial direction, where the decision to integrate or not reflects a tradeoff between motivation and coordination. An informal statement of the tradeoff between motivation and coordination can also be found in Roberts (2004: 103-108).

As importantly, the above model shows how moral hazard theories of the firm can deliver a number of testable and intuitive predictions. Noteworthy are those related to contractibility of performance dimensions. While our results suggest that a better contractibility of output measures favors using the market (nonintegration), this is not necessarily the case for the contractibility of input costs. A better contractibility of costs mitigates agency problems both within firm boundaries, by allowing for more higher powered incentives for cost reduction, and between firm boundaries, by allowing for more effective cost-plus contracting and, hence, better coordination.

\section{Control Theories of the Firm}

Moral hazard models make the extreme assumption that task allocation is fixed exogenously, and agents cannot be removed/replaced when they do not follow task directions. In reality, many important decisions taken by employees can be overturned by the firm's owners or their designated managers through the direct or indirect use of their residual control rights. Indeed, firm owners and top management tend to exercise residual control rights through selective intervention: they intervene when em-

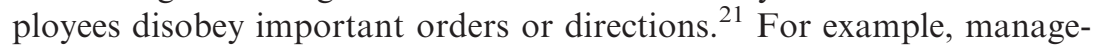
ment may deny an employee access to assets necessary for implementing decisions, funding or personnel may be withdrawn, or the employee may be fired, replaced, or re-assigned. While control models share the assumption of moral hazard models that certain decisions are noncontractible, they take the polar position that those decisions are fully controlled by the firm owners, or their designated managers. ${ }^{22}$

21. One justification for the assumption in moral hazard models is that actions are not only noncontractible, but also nonobservable, and hence selective intervention is not feasible.

22. An implicit assumption is further that authority over actions cannot simply be transferred contractually - ownership of assets and, hence, firm boundaries must matter. See Baker et al. (2011) for a model in which contracts are used to move control rights across fixed firm boundaries. 
A straightforward implication from control models might seem that asset ownership, and hence control, should be allocated to the party whose interests are most aligned with total surplus maximization. Gibbons (2005: 212-213), for example, provides a formal model along those lines. ${ }^{23}$ Taken literally, however, Gibbon's model is more a theory of who should own the assets of the firm, rather than what are the boundaries of that firm.

A more powerful insight obtains when firm boundaries determine the objectives of the firm owners - rather than the other way around. In particular, if firm owners can appropriate the noncontractible returns on the assets of the firm, as is the case in moral hazard models, it follows quite naturally that centralized asset ownership results in a better coordination of decisions than dispersed asset ownership. Some well-known papers that follow this logic to elucidate firm boundaries include Stein (1997) on internal versus external capital markets, and Hart and Holmstrom (2010) (HH hereafter) on firm scope. ${ }^{24}$ In Stein (1997), integration results in a better ex post allocation of capital, but comes at the expense of reduced incentives for business unit managers. ${ }^{25} \mathrm{In} \mathrm{HH}$, the owners of integrated firms are better at exploiting economies of scale through standardization, but they do not internalize the private benefits of managers of individual business units. Both control models have in common that, in the presence of externalities, concentrated asset ownership may be valuable for coordination purposes.

In this section, I show how the improved coordination in integrated firms, highlighted in $\mathrm{HH}$, may come at the expense of worse adaptation to a changing environment. For this purpose, I introduce asset ownership in the model of Alonso et al. (2008) (ADM hereafter). ${ }^{26}$ As in $\mathrm{HH}$, decisions benefit from being coordinated in ADM, but the model introduces the notion that decisions need to be adapted to an uncertain environment. $^{27}$

23. See also Bester (2009) for a related model that focuses on the allocation of decision rights in an organization, but can be reinterpreted in terms of asset ownership.

24. As in other control models, $\mathrm{HH}$ assume that parties simply exercise their decision rights without any bargaining with side payments. Rather than appealing to noncontractibility, they informally justify the no bargaining assumption by introducing "shading" (Hart and Moore 2008) in their model. An earlier version did not refer to shading, but simply assumed noncontractibility.

25. See also Scharfstein and Stein (2000), Rajan et al. (2000), Stein (2002), Brusco and Panunzi (2005), Inderst and Laux (2005), and Friebel and Raith (2010).

26. See also Rantakari (2008).

27. In contrast, uncertainty plays no role in HH's theory of firm scope. Decision-making is assumed to deviate from ex post surplus maximization for different reasons under integration and nonintegration, and the question in $\mathrm{HH}$ is which inefficiency is the largest. Introducing uncertainty in their model would not alter this tradeoff. 


\subsection{Adaptation and Firm Boundaries}

Adaptation to a changing and uncertain environment is a central issue in transaction cost economics. As stated by Williamson (1985: 56):

many of the interesting issues with which transaction cost economics is involved reduce to an assessment of adaptive, sequential decision-making [...] the basic proposition here is that governance structures differ in their capacities to respond effectively to disturbances.

In arguing that "adaptation is the central problem," Williamson (1996, 2002) frequently cites Hayek who famously maintained that "the economic problem of society is mainly one of adaptation to changes in particular circumstances of time and place" (Hayek 1945: 524). Hayek's argument, however, was very much that the market has adaptive capabilities, which are superior to that of a centrally planned economy. Hayek emphasized not only the role of the price system in coordinating economic activity, but also that most decision-relevant information is dispersed and local in nature. In settings in which the relevant information is dispersed, it is far from clear why a centralized or integrated organization would be better at adapting to a changing environment than a decentralized or non-integrated organization. ${ }^{28}$

Section 3.2 proposes a modified version of ADM to address the above question. In line with Hayek's focus on local information, the model assumes that the decision-relevant information is dispersed. Concretely, let there be two assets, one can think of two business units, each operated by a different agent who is privately informed about some local information pertaining to his unit. Each unit must implement a major decision whose effectiveness depends on how adaptive it is to the local information and how well coordinated it is with the decision of the other unit. Agents are employees, however, who do not own the assets they operate. They must therefore communicate their local information to the owner or owners of the business units, who control major decisions. ${ }^{29}$ The question is whether there should be common ownership of assets with a single "boss" for both agents, or dispersed ownership with each agent having his own boss.

If there were no communication frictions between the employees and the owners, concentrated ownership with a single boss would always be optimal. Indeed, such a single owner would then internalize all externalities between business units. Incentive conflicts between the firm owner and the agents who operate the business units, however, may make

28. For example, many business practitioners have advocated that firms decentralize decision-making in more competitive and turbulent environments. Some empirical evidence, such as Bloom et al. (2009), is consistent with this.

29. Following the literature on firm boundaries, and in contrast to ADM or Dessein (2002), I assume that decision rights cannot be credibly delegated to employees. Decisions are therefore always taken by asset owners and I assume that an employee cannot be an owner. 
communication strategic and noisy. ${ }^{30}$ Concretely, I assume that each agent maximizes the returns of the unit he operates, for example, because of the career concerns or implicit incentives. In contrast, firm boundaries determine the objectives of the firm owners, who maximize the returns of the unit(s) under their control.

The optimal ownership structure is then driven by a tradeoff between coordination and adaptation. Common ownership (integration) is valuable, as the single firm owner then internalizes externalities and ensures coordination. Common ownership, however, also results in decisions that are not very adaptive to local information, as the employees and the firm owner do not share the same objectives and, hence, communication is strategic and noisy. Important local information is thus lost under integration. In contrast, under dispersed ownership (nonintegration), each firm owner shares a common objective with his employee, and communication is friction-less. Owners of individual assets are then able to accurately adapt decisions to local information, but may fail to coordinate their decisions. $^{31}$

Relative to $\mathrm{GH}$, the proposed control model emphasizes the role of a central office or a common owner in coordinating decisions under integration. However, it also highlights the benefits of nonintegration in being more responsive to a changing environment. The adaptive benefits of markets (i.e., dispersed asset ownership) can be contrasted with the entrepreneurial and incentivizing benefits emphasized in standard property rights or moral hazard models.

\subsection{A Control Theory of the Firm}

The following control model is adapted from ADM to include asset ownership. Consider two business units, 1 and 2, which can either be stand-alone firms, or belong to one and the same firm. Business Unit $j \in\{1,2\}$ generates profits that depend on its local conditions, described by $\theta_{j} \in \mathbf{R}$, and on two decisions, $d_{1} \in \mathbf{R}$ and $d_{2} \in \mathbf{R}$. In particular, the profits of Business Unit 1 are given by

$\pi_{1}=K_{1}-\alpha\left(d_{1}-\theta_{1}\right)^{2}-\delta\left(d_{1}-d_{2}\right)^{2}$,

where $K_{1} \in \mathbf{R}_{+}$is the maximum profit that the unit can realize. The first squared term captures the adaptation loss that Unit 1 incurs, if decision $d_{1}$

\footnotetext{
30. Stein (2002) and Friebel and Raith (2010) also consider dispersed information and strategic communication in models of resource allocation. Resource reallocation is assumed to be only feasible in integrated firms, however. Horizontal coordination and communication are therefore ruled out. In contrast, in ADM, the same production possibilities are feasible under both integration and nonintegration.

31. Consistent with ADM, Simester and Knez (2002) provide evidence about a high-technology firm which indicates that the firm enjoys better coordination with its internal supplier, and that this partially determines which parts are made internally. As in the model, a major reason is that communication is much more distorted and strained, for strategic reasons, when it occurs across firm boundaries rather than within the firm.
} 
is not perfectly adapted to its local conditions, that is if $d_{1} \neq \theta_{1}$, and the second squared term captures the coordination loss that Unit 1 incurs, if the two decisions are not perfectly coordinated, that is if $d_{1} \neq d_{2}$. Coordination benefits can be interpreted as economies of scope when the two business unit choose more standardized processes, use more common inputs, or are more compatible with each other. I refer to ADM (as well as $\mathrm{HH}$ ) for more discussion on the interdependence parameter $\delta$. The parameter $\delta / \alpha \in[0, \infty)$ then measures the importance of coordination relative to adaptation. The profits of Unit 2 are similarly given by

$\pi_{2}=K_{2}-\alpha\left(d_{2}-\theta_{2}\right)^{2}-\delta\left(d_{1}-d_{2}\right)^{2}$,

where $K_{2} \in \mathbf{R}_{+}$is the maximum profit that Unit 2 can realize.

3.2.1 Information. Each Unit is run by an employee. Agent 1, the employee in charge of Unit 1, privately observes his local conditions $\theta_{1}$ but does not know the realization of $\theta_{2}$. Similarly, Agent 2, the employee in charge of Unit 2, observes $\theta_{2}$ but does not know $\theta_{1}$. It is common knowledge, however, that $\theta_{1}$ and $\theta_{2}$ are uniformly distributed on $\left[-s_{1}, s_{1}\right]$ and $\left[-s_{2}, s_{2}\right]$, respectively, with $s_{1}$ and $s_{2} \in \mathbf{R}_{+}$, where the draws of $\theta_{1}$ and $\theta_{2}$ are independent. The private benefits of each employee are further assumed to be proportional to the profits of his unit, for example, because he can divert part of the profits of the unit as in Stein (1997) or HH. Note that this assumption can easily be endogenized by adding career concerns or a moral hazard problem to the model, where the profits of a business unit depend on the talent and/or effort of the employee.

3.2.2 Firm Boundaries and Asset Ownership. Following GH, firm boundaries matter as contracts are highly incomplete and asset ownership provides residual control and residual income rights. In particular, I assume that there are two clusters of assets: the assets of business Unit 1 and the assets of business Unit 2. While $d_{1}$ and $d_{2}$ are noncontractible, ownership of the assets of business unit $i=1,2$, provides control over $d_{i}$. Similarly, profits are noncontractible but ownership of the assets of business unit $i$ provides residual income rights over $\pi_{i}$. This assumption follows Hart (1988), Holmstrom and Milgrom (1991, 1994), Stein (1997), and HH.

Two ownership configurations are possible: business Units 1 and 2 are jointly owned (integration), or business Units 1 and 2 are independently owned (nonintegration). For simplicity, I assume that Agents 1 and 2 cannot be asset owners, for example, because they are liquidity constrained. Given the above assumptions, under nonintegration, the owner of business Unit 1 (Owner 1) chooses $d_{1}$ and maximizes $\pi_{1}$ and owner of business Unit 2 (Owner 2) chooses $d_{2}$ and maximizes $\pi_{2}$. Under common ownership (integration), the common owner chooses $d_{1}$ and $d_{2}$ and maximizes $\pi_{1}+\pi_{2}$. 
3.2.3 Communication. Since $d_{1}$ and $d_{2}$ are noncontractible, decisionmakers are not able to commit to paying transfers that depend on the information they receive or to make their decisions depend on such information in different ways. Communication between the owner or owners and their better-informed employees therefore takes the form of an informal mechanism: cheap talk (Crawford and Sobel 1982). I assume that both Agents 1 and 2 send a private message to whoever owns their business unit. Under integration, Agent $i$ and the common owner then have different objectives. As a result, communication is noisy, and, as is common in the literature, I will focus on the most informative communication equilibrium. In contrast, under nonintegration, Agent $i$ and Owner $i$ share the same objectives. Hence, there exists an equilibrium in which owner $i$ perfectly learns $\theta_{i}$. Under nonintegration, Owners 1 and 2 may also benefit from communicating with each other in order to coordinate their choices of $d_{1}$ and $d_{2}$. I assume, therefore, that Owners 1 and 2 simultaneously send a message to each other after communicating with their agent. ${ }^{32}$ Since Owners 1 and 2 have different objectives, this communication will be noisy and, again, I will focus on the most-informative cheap talk equilibrium.

The game is summarized in Figure 2. First, asset ownership is allocated to maximize total expected profits $\mathrm{E}\left[\pi_{1}+\pi_{2}\right]$. Under Integration, there is one owner who controls both decisions. Under nonintegration, there are two owners who each control a different decision. Second, the two agents who operate the business units become informed about their local conditions, i.e., they learn $\theta_{1}$ and $\theta_{2}$, respectively. Third, the agents privately communicate with the owner of their business unit. Under nonintegration, the owners also communicate with each other. Finally, the decisions $d_{1}$ and $d_{2}$ are made by the owner(s). Each decision-maker chooses the decision that maximizes his payoff given the information that has been communicated.

\subsection{Firm Boundaries: Adaptation Versus Coordination}

The tradeoff between integration (common ownership) and nonintegration (dispersed ownership) is now relatively straightforward: under nonintegration, objectives of the owners and the employees are aligned and

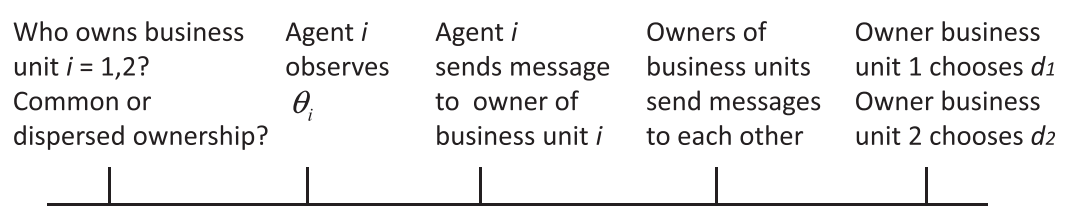

Figure 2. Time-line Control Model.

32. Alternatively, under nonintegration, each Agent $i=1,2$ could send a private message $m_{i j}$ to each Manager $j=1,2$. 
communication is fluent. In contrast, under integration, objectives of the common owner and employees are nonaligned, and communication is noisy.

Profits under nonintegration, then, are as if employees effectively control decision-making. They are therefore equivalent to the decentralization case in ADM with fully biased managers. Similarly, profits under integration are equivalent to those under centralization in ADM. The only difference with ADM is that decision rights are never formally delegated to employees. The objectives of an employee's boss, however, depend on firm boundaries and determine how much real authority an employee has. ${ }^{33}$

Given the above equivalence, I can refer to ADM for a formal characterization of decision-making and communication equilibria under integration (centralization) and nonintegration (decentralization in ADM). Proposition 3 in ADM highlights an important tradeoff between integration and nonintegration. On the one hand, under nonintegration, Owner $i$ is better informed about $\theta_{i}$ than the common owner under integration, as the latter must rely on noisy intrafirm communication. One can say that owner $i=1,2$, has better specialized knowledge than the common owner. On the other hand, the common owner is better informed about $\theta_{j}$ than Manager $i \neq j$. Indeed, for any $\delta \geqslant 0$, intrafirm communication under integration is more informative than interfirm communication under nonintegration. One can say that the common owner has broader knowledge than Owner 1 or 2 . It follows that the common owner is better able to coordinate $d_{1}$ and $d_{2}$. A first insight is thus that common ownership results in broader knowledge by decision-makers, whereas dispersed ownership results in deeper and more specialized knowledge by decision-makers.

Beyond the (equilibrium) differences in their information structure, the common owner and the individual owners also have different objectives. While the common owner maximizes joint expected profits in choosing $d_{1}$ and $d_{2}$, the owners of individual business units maximize expected profits of their unit, and do not take externalities into account. As a result, the decisions of Owners 1 and 2 are too responsive to their information relative to the first-best.

It follows that integrated firms are better at coordinating decisions than nonintegrated firms: $d_{1}$ and $d_{2}$ are more correlated under integration (common ownership) than under nonintegration (dispersed ownership). In contrast, under nonintegration, individual decisions are typically more correlated with the local information of their unit. The above logic suggests that integration will be preferred if and only if coordination is

33. Put differently, the ownership structure affects the real authority of agents and, hence, their incentives for information revelation. The real authority of an employee may also affect his incentives for information acquisition, as emphasized in Aghion and Tirole (1997). Introducing the need for information acquisition in the model would further enhance the benefits of nonintegration. 
sufficiently important relative to adaptation. The following proposition, which is taken directly from ADM, shows that this is indeed the case.

Proposition 6. There exists a $\bar{\delta}>0$ such that Integration (common ownership) is strictly preferred if $\delta / \alpha>\bar{\delta}$ and nonintegration (dispersed ownership) is strictly preferred if $\delta / \alpha \in(0, \bar{\delta})$.

While the idea that integrated firms may be better at coordinating decisions is also present in Stein (1997), Hart and Moore (2005), and HH, the novel contribution of the above control model is the focus on the ability of nonintegrated firms to adapt to a changing environment. As such, the model gives content to the broad idea that information gets lost and distorted in large bureaucratic firms. The adaptive benefits of nonintegrated firms, highlighted in the above model, can be contrasted with the entrepreneurial and incentivizing benefits of nonintegrated firms emphasized in GH and PRT.

\section{Conclusion}

This article has discussed some new directions in the theory of the firm that emphasize the role of bureaucratic decision-making and centralized asset ownership in coordinating and directing economic activity. Following Grossman and Hart (1986), firm boundaries are defined based on the ownership of nonhuman assets, and the costs and benefits of integration are analyzed in a unified framework. The new approaches differ from Grossman and Hart, however, on at least two dimensions. First, actions are noncontractible and firm boundaries determine what actions are eventually undertaken. In contrast, the assumption of ex post contractibility and Coasian bargaining in Grossman and Hart implies that ex-post decision-making is always efficient, regardless of the ownership structure. Second, asset ownership not only provides residual control rights, but also directly affects objectives: firm owners can appropriate the returns on the assets they own, and are responsible for the financial outlays associated with providing and maintaining the assets necessary for production. While there may exist contractible cost and revenue measures, these are not a perfect substitute for asset ownership.

In both approaches discussed, centralized or common asset ownership implies a better coordination of actions and decisions. The reason is that centralized asset ownership allows or facilitates managerial direction or command, and ensures that firm owners take externalities between decisions into account. The models therefore introduce management and bureaucratic decision-making inside a theory of the firm. Those coordination benefits of common ownership are contrasted with the benefits of dispersed asset ownership in providing higher powered incentives (which, however, reduce coordination) and a better adaptation of decisions to an uncertain and changing environment (which require decentralized decision-making and therefore, again, reduce coordination). 
A major shortcoming of this essay is its lack of attention to at least three recent strands in the incomplete contracting literature. First, a few papers, such as Matouschek (2004), have introduced asymmetric information in the context of standard property rights models. Ex post bargaining is then not friction-less anymore and, hence, the allocation of residual control rights matters for ex post efficiency. Second, Hart and Moore (2008) and Hart (2009) introduce some behavioral elements where agents "shade" their performance, if they feel mistreated in the contract execution stage. Asset ownership may play a role here to the extent it affects such feelings of entitlement. Again this strand of literature introduces ex post inefficiencies in a theory of the firm. Finally, I have ignored dynamic considerations and relational contracts (Baker et al. 2002, 2011; Levin 2002), which can be fruitfully applied to shed light on firm boundaries. While the above papers contain many valuable insights, this essay has instead focused on models that introduce a clear role for managerial direction and bureaucratic decision-making in a theory of the firm.

\section{References}

Acemoglu, D., P. Aghion, R. Griffith, and F. Zilibotti. 2010. "Vertical Integration and Technology: Theory and Evidence," 8 Journal of the European Economic Association 989-1033.

Aghion, P., and J. Tirole. 1997. "Formal and Real Authority in Organizations," 105 Journal of Political Economy 1-29.

Aghion, P., and R. Holden. 2011. "Incomplete Contracts and the Theory of the Firm: What Have We Learned Over the Past 25 years?" 25 Journal of Economic Perspectives 181-97.

Alchian, A., and H. Demsetz. 1972. "Production, Information Costs, and Economic Organization," 62 American Economic Review 777-95.

Alonso, R., W. Dessein, and N. Matouschek. 2008. "When Does Coordination Require Centralization?" 98 American Economic Review 145-79.

Athey, S., and J. Roberts. 2001. "Organizational Design: Decision Rights and Incentive Contracts," 91 American Economic Review 200-5.

Bajari, P., and S. Tadelis. 2001. "Incentives Versus Transaction Costs: a Theory of Procurement Contracts," 15 Rand Journal of Economics 385-95.

Baker, G., R. Gibbons, and K. J. Murphy. 2002. "Relational Contracts and the Theory of the Firm," 117 Quarterly Journal of Economics 39-83.

_. 2011. "Relational Adaptation," Working Paper, MIT.

Baker, G., and T. Hubbard. 2003. "Make Versus Buy in Trucking: Asset Ownership, Job Design, and Information," 93 American Economic Review 551-72.

. 2004. "Contractibility and Asset Ownership: On-Board Computers and Governance in U.S. Trucking," 119 Quarterly Journal of Economics 1443-79.

Bhattacharyya, S., and F. Lafontaine. 1995. "Double-side Moral Hazard and the Nature of Share Contracts," 26 Rand Journal of Economics 761-81.

Bloom, N., R. Sadun, and J. Van Reenen. 2009. "The Organization of Firms Across Countries," Working Paper, LSE.

Bester, H. 2009. "Externalities, Communication and the Allocation of Decision Rights," 41 Economic Theory 269-96.

Brusco, S., and F. Panunzi. 2005. "Reallocation of Corporate Resources and Managerial Incentives in Internal Capital Markets," 49 European Economic Review 1659-81.

Coase, R. 1937. "The Nature of the Firm," 4 Economica 386-405. 
Crawford, V., and J. Sobel. 1982. "Strategic Information Transmission," 50 Econometrica $1431-51$.

Dessein, W. 2002. "Authority and Communication in Organizations," 69 The Review of Economic Studies 811-38.

Dessein, W., L. Garicano, and R. Gertner. 2010. "Organizing for Synergies," 2 American Economic Journal: Microeconomics 77-114.

De Meza, D., and B. Lockwood. 1998. "Does Asset Ownership Always Motivate Managers? Outside Options and the Property Rights Theory of the Firm," 113 Quarterly Journal of Economics 361-86.

Furubotn, E., and S. Pejovich. 1974. The Economics of Property Rights. Cambridge, MA: Ball- inger.

Friebel, G., and M. Raith. 2010. "Resource Allocation and Organizational Form," 2 American Economic Journal: Microeconomics 1-33.

Gibbons, R. 2005. "Four Formal(izable) Theories of the Firm?" 58 Journal of Economic Behavior and Organization 200-45.

Grossman, S., and O. Hart. 1986. "The Costs and Benefits of Ownership: A Theory of Vertical and Lateral Integration," 94 Journal of Political Economy 691-19.

Hart, O. 1988. "Contracts and the Theory of the Firm," 4 Journal of Law, Economics and Organization 119-39.

1995. Firms, Contracts, and Financial Structure. Oxford: Clarendon Press.

. 2009. "Hold-up, Asset Ownership, and Reference Points," 124 Quarterly Journal of Economics 301-48.

Hart, O., and B. Holmstrom. 2010. "A Theory of Firm Scope," 125 Quarterly Journal of Economics 483-513.

Hart, O., and J. Moore. 1990. "Property Rights and the Nature of the Firm," 98 Journal of Political Economy 1119-58.

- 2005. "On the Design of Hierarchies: Coordination Versus Specialization," 113 Journal of Political Economy 675-702.

2008. "Contracts as Reference Points," 123 Quarterly Journal of Economics 1-48.

Hayek, F. 1945. "The Use of Knowledge in Society," 35 American Economic Review 519-30.

Holmstrom, B. 1999. "The Firm as a Subeconomy," 15 Journal of Law, Economics and Organization 74-102.

Holmstrom, B., and P. Milgrom. 1987. "Aggregation and Linearity in the Provision of Intertemporal Incentives,” 55 Econometrica 303-28.

- 1991. "Multitask Principal-agent Analysis: Incentive Contracts, Asset Ownership, and Job Design," 7 Journal of Law, Economics and Organization 24-52.

_. 1994. "The Firm as an Incentive System," 84 American Economic Review 972-91.

Holmstrom, B., and J. Roberts. 1998. "The Boundaries of the Firm Revisited," 12 Journal of Economics Perspectives 73-94.

Holmstrom, B., and J. Tirole. 1989. "The Theory of the Firm," in R. Schmalensee, and R. Willig, eds., Handbook of Industrial Organization. Amsterdam: North-Holland.

Inderst, R., and C. Laux. 2005. "Incentives in Internal Capital Markets: Capital Constraints, Competition, and Investment Opportunities," 36 Rand Journal of Economics 215-28.

Lafontaine, F., and M. Slade. 2007. "Vertical Integration and Firm Boundaries: the Evidence," 45 Journal of Economic Literature 629-85.

Levin, J. 2002. "Multilateral Contracting and the Employment Relationship," 117 Quarterly Journal of Economics 1075-103.

Marino, A., J. Matsusaka, and J. Zabjonik. 2010. “Disobedience and Authority,” 26 Journal of Law, Economics and Organization 427-59.

Matouschek, N. 2004. "Ex post Inefficiencies in a Property Rights Theory of the Firm," 20 Journal of Law, Economics and Organization 125-47.

Rajan, R., H. Servaes, and L. Zingales. 2000. "The Cost of Diversity: The Diversification Discount and Inefficient Investment," 55 Journal of Finance 35-80. 
Rajan, R., and L. Zingales. 1998. "Power in a Theory of the Firm," 113 Quarterly Journal of Economics 387-432.

Rantakari, H. 2008. "Governing Adaptation,” 75 Review of Economic Studies 1257-85.

Roberts, J. 2004. The Modern Firm: Organizational Design for Performance and Growth. Oxford: Oxford University Press.

Scharfstein, D., and J. Stein. 2000. "The Dark Side of Internal Capital Markets: Divisional Rent-seeking and Inefficient Investment,” 55 Journal of Finance 2537-64.

Simester, D., and M. Knez. 2002. "Direct and Indirect Bargaining Costs and the Scope of the Firm," 75 Journal of Business 283-304.

Stein, J. 1997. "Internal Capital Markets and the Competition for Corporate Resources," 52 Journal of Finance 111-33.

—. 2002. "Information Production and Capital Allocation: Decentralized Versus Hierarchical Firms," 57 Journal of Finance 1891-921.

Tadelis, S. 2003. "Complexity, Flexibility, and the Make-or-buy Decision," 92 American Economic Review 433-7.

Van den Steen, E. 2007. "The Cost of Incentives Under Disagreement: Too Motivated?" Working Paper, Harvard Business School.

- 2010. "Interpersonal Authority in a Theory of the Firm," 100 American Economic Review 466-90.

Whinston, M. 2003. "On the Transaction Cost Determinants of Vertical Integration," 19 Journal of Law, Economics and Organization 1-23.

Whinston, M., and I. Segal. 2010. "Property Rights," Working Paper, Northwestern University.

Williamson, O. 1971. "The Vertical Integration of Production: Market Failure Considerations," 61 American Economic Review 112-23.

- 1975. Markets and Hierarchies: Analysis and Antitrust Implications. New York, NY: Free Press.

1985. The Economic Institutions of Capitalism. New York, NY: Free Press.

1991. "Comparative Economic Organization: The Analysis of Discrete Structural Alternatives," 36 Administrative Science Quarterly 269-96.

. 2002. "The Theory of the Firm as Governance Structure: From Choice to Contract," 16 Journal of Economic Perspectives 171-95.

Woodruff, C. 2002. "Noncontractible Investments and Vertical Integration in the Mexican Footwear Industry," 20 International Journal of Industrial Organization 1197-224. 